\title{
Students' Attitude towards Virtual Learning during Covid-19 in Chitwan
}

\author{
Sharada Khanal \\ Asst. Lecturer \\ Department of English, Balkumari College \\ ghimiresharada2073@gmail.com
}

\begin{abstract}
The COVID-19 pandemic is rapidly accelerating the learning process. As a result, there has been a shift from face- to- face to virtual learning. The major purpose of this research was to identify the interest and attitude of students towards virtual learning during covid-19 pandemic. The study was to determine whether students are interested in virtual learning or not. This survey is based on primary data collected from students who are currently pursuing their degrees. Google form structured questionnaire was distributed via Messenger app to the students of Chitwan district colleges where virtual learning is going on using random sampling method. The result revealed that students are interested in virtual learning. The majority of students found it as an important means of making knowledge widerand bringing social changes despite hindrances $(p=0.001)$. Virtual learning is a powerful tool for teaching replacing face to face learning in any level as a quick solution to the crisis. However, successful implementation of virtual learning into curriculum requires a well thoughtout strategy and equal access of all.
\end{abstract}

Keywords: COVID-19 pandemic, virtual learning, education.

\section{Introduction}

A virtual learning environment is a web-based platform in educational technology that focus on the digital courses of study within educational institutions presenting resources, activities, and interactions within a course structure for the stages of assessment(Wikipedia). Personal computers and the Internet have revolutionized entire sectors of society. Facebook, twitter, YouTube, Skype, Whatsapp, WebEx, zoom, and other online communications media help billions of people around the world to share ideas in a matter of seconds in a cost effective way. Even then there are some problems because some people are unaware of how computers internet technology are transforming the way the students learn. However this emerging trend of virtual learning has the potential to improve students' achievement, educational access and so on. In the context of present ongoing Covid-19 pandemic, there is a forced immersion of learners into virtual learning replacing face-to-face learning method as a quick solution to the crisis(Abbasi \& et.al., 2020). "The COVID-19 pandemic has created the largest disruption of education systems in history, affecting nearly 1.6 billion learners in more than 190 countries and all continents. Closures of schools and other learning spaces have impacted 94 per cent of the world's student population, up to 99 per cent in low and lower-middle income countries" (Natoins, 2020).

The pandemic adds a further complexity in the field of higher education globally especially in the developing countries where there are unresolved challenges like growth without quality, inequality in access and achievement and the progressive loss of public financing. Particularly, those students on the verge of finishing high school and aspiring to begin tertiary education and undergraduates will have the immediate effect in accordance with their profiles, irrespective of their socioeconomic background and geographic situation (UNESCO, 2020). Amid the COVID-19 pandemic and the need for social distancing, this virtual learning platform has significantly reshaped and innovated how we teach and engage with our students. In addition, it has allowed us to continue to foster a sense of community that we hope can attenuate students' burnout and promote wellness in a time when isolation has become a part of everyday life. Program specific virtual learning platforms have the potential to play an importantand useful role in the teaching learning process(Almarzooq, Lopes, \& Kochar, 2020). Though online learning is effective in digitally advanced societies it cannot produce desired results in under developed countries because a vast majority of students are unable to access the internet due to technical as well as financial problem(Adnan \& Anwar, 2020). 


\section{Statement of the Problem}

Even though a great number of studies and research projects in virtual learning have been conducted, the research on students' interest and attitude towards virtual learning during covid-19 pandemic especially in Chitwan has not been done yet. In this sense, there is a need for further research about perception of students of Chitwan including various colleges in order to identify the solution of the research question like: Are students interested in virtual learning? Does virtual learning improve their skills? Does virtual learning make their lockdown time a useful one?

\section{Significance of the Study}

This study will help to find out the students' attitude towards virtual learning during covid-19 pandemic. This study was done for the students who are studying in various colleges and universities and even schools of Chitwan with a view to gain additional information regarding the contribution of virtual learning during pandemic. Digital technology can be a good learning paradigm in educational institutions to enhance the students' knowledge and skills through digital technologies.

\section{Objectives of the Study}

This research aims to find out the global trend of virtual learning resources among Chitwan students. The following are the specific objectives:

- To identify the interest and attitude of students towards using virtual learning resources.

- To suggest prospects in using virtual learning resources by students.

\section{Review of the Literature}

Virtual learning has been the area of interest for many researchers and educators in order to enhance and improve student learning outcome while combating the reduction in resources particularly in higher education. The physical "brick and mortar" classroom is starting to lose its monopoly at the place of learning (Nguyan, 2015). Traditionally, learning environments are defined in terms of time, place and space. Conversely, virtual learning environment provides high level of student control, support of participant contact and interaction throughout the learning process. Moreover, it can potentially eliminate geographical barriers. It has got significant impact on the learning industry on a whole (Piccoli, Ahmad, \& Ivs, 2001). An important extension of the system to add a module for knowledge level estimation of the students by using software agents that manage to provide a certain transparency of the physical allocation of the hosts in system (Kimovski, Trajkovic, \& Davcev, 2001).

Muhammad (2020) concluded $71.4 \%$ students reported that learning in the conventional classroom was more motivating than virtual learning. Even then the majority of the students can manage their time effectively online and can easily complete assignments in time. Abbasi (2020) found that mobile has become popular device among students for virtual learning as compared to laptops and tablets. Students have found it less appealing due to its limitation with respect to practical aspects of learning. Despite gaining immense popularity today digital technology has still not been embraced by the Medical and Dental students in teaching learning process. As per the World Economic Forum the Covid-19 pandemic also has changed the way how several people receive and impart education. Teachers have become habitual to traditional methods of teaching in the form of face-to-face lectures and they therefore try to avoid the change. But amidst this crisis, as there is no other alternative left over than adapting to the dynamic situation. It has become beneficial for the education sector and brought a lot of surprising innovations (Dhawan, 2020).

"Virtual learning is an excellent option in education, particularly when there are hindrances to traditional learning situations" (Dhull \& Sakshi, 2017). "The survey indicated that between 60 to 80 per cent of the syllabus has been covered by using online teaching methods according to a majority of students. Only one-fifth of the students stated that they could cover between 40 to 60 per cent of their syllabus during lockdown with the assistance of online teaching modes. Next, it came to light that the learners have encountered several problems in learning with online modes. The biggest among them is 'Poor internet connectivity problem' followed closely by 'the problem in choosing best source amongst many'. Non availability and non-affordability for e-learning resources, lack of technical skills and electricity issues are the other problems(Amita, 2020).

Thus, above paragraphs indicate virtual learning is a temporary aid during difficult situation that we are facing. 
The Covid-19 pandemic has posed significant concern among students. The pandemic related challenges add additional layer of complexity because many students are from remote area with minimal access to electronic devices and reliable internet connectivity or stable electricity supply. The Covid-19 is rapidly accelerating the remote workplace especially there is the shift from classroom to virtual learning.

The review of literature has shown various studies have been conducted to identify and assess perceptions and attitude of the e-learners towards e-learning. The research gap is found when it comes to study attitude of students towards virtual learning during Covid-19 pandemic situation in Chitwan.

\section{Research Methods}

This study is based on cross sectional survey method. The method of sampling technique was random covering the students of Chitwan district +2 , bachelor and master degree colleges where students are currently attending online classes. The sample size was 224. Google form questionnaire incorporating 3 likert scale questions and demographic items was used to gather data about attitude of students regarding virtual learning during Covid-19 pandemic taking one month time period. The data were analyzed in frequency table, cross table and graphic representation.

\section{Result and Discussion}

\section{A. Demography Presentation:}

Table no. 1: Demographic presentation of gender, age and parent's occupation

\begin{tabular}{|l|c|c|}
\hline Gender & Numbers & Percentage \\
\hline Fale & 121 & 54.1 \\
\hline Age & 103 & 45.9 \\
\hline Less than 18 & 29 & \\
\hline $18-20$ & 93 & 12.94 \\
\hline $20-22$ & 50 & 41.5 \\
\hline $22-24$ & 37 & 22.3 \\
\hline Above 25 & 15 & 16.52 \\
\hline Parent's Occupation & & 6.7 \\
\hline Agriculture & 80 & 35.8 \\
\hline Business & 46 & 20.5 \\
\hline Private Job & 31 & 13.8 \\
\hline Foreign & 22 & 9.8 \\
\hline Government & 20 & 8.9 \\
\hline Others & 25 & 11.2 \\
\hline
\end{tabular}

In table no.1 demonstrates among 224 respondents 121(54.1\%) are male. It projects age group of 18-20 in highest in number $93(41.5 \%)$. The age group of 20-22, 22-24, and above 25 are found decreasing order in number. In this sense, virtual learning was found applied mostly in bachelor level during the COVID-19 pandemic. Similarly, it projects among total sampling, 80 respondents are from agricultural background. 46 means 20.4 percentages are of business class family. 31 Respondents' parents have private job. Likewise, 22 respondents' parents have foreign job. 20 have government job holding parents. These shows in Chitwan area majority of the students are from agriculture based family. It is because the main profession of Nepalese people is still agriculture (Gautam, 2008). 


\section{B. Tools used for virtual classes}

\section{Tools for Virtual Learning}

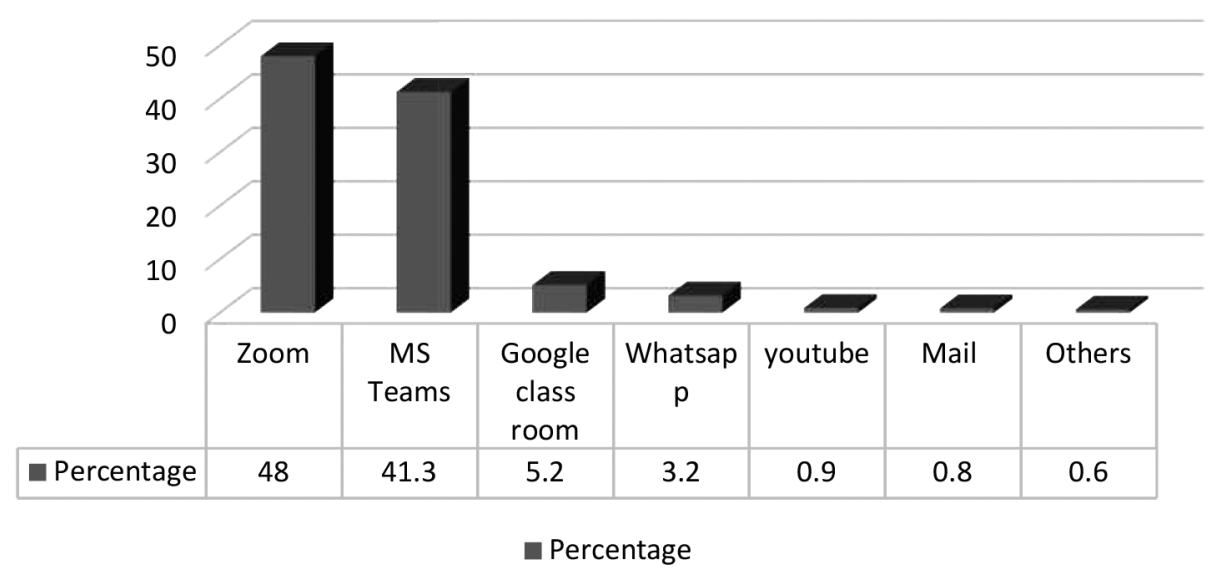

Figure no.1: Tools Used for Virtual Learning

The above Figure no.1 reflects that $48 \%, 41.3 \%, 5.2 \%, 3.2 \%, 0.9 \%, 0.8 \%$ and $0.6 \%$ respondents used zoom, MS Teams, Google classroom, What Sapp, YouTube, mail, and others for learningpurpose during pandemic. Majority of the students used zoom app because it is popular, convenient and easy especially during this Covid-19 pandemic(Gallagher, 2020).

\section{Overall perception and category wise responses of students towards virtual learning.}

Table no.2: Students' Responses towards Virtual Learning

\begin{tabular}{|l|c|c|c|}
\multicolumn{1}{c}{ Attitude Scale } & \multicolumn{1}{c}{$\begin{array}{c}\text { Agree } \\
(\mathbf{\%})\end{array}$} & $\begin{array}{c}\text { Somehow } \\
\text { Agree (\%) }\end{array}$ & $\begin{array}{c}\text { Disagree } \\
(\%)\end{array}$ \\
\hline Feel qualified to use computer/laptop & 61.6 & 6.7 & 31.7 \\
\hline No difference between online and Conventional learning & 12 & 63.6 & 24.4 \\
\hline Complete course can be completed effectively through internet & 21 & 54.9 & 24.1 \\
\hline Be comfortable communicating electronically & 57.3 & 14.2 & 28.4 \\
\hline Easy to complete group projects/assignments digitally & 39.4 & 30.4 & 30.7 \\
\hline Necessity of face to face contact with instructor in learning & 70.7 & 11.1 & 18.2 \\
\hline Online classes and modules are boring & 33.6 & 35.8 & 30.5 \\
\hline Have easy internet access & 19.9 & 65.9 & 14.2 \\
\hline Have Personal smartphones and computers & 15.9 & 12.8 & 71.3 \\
\hline Online learning is more motivating than conventional learning & 13.5 & 23.8 & 62.8 \\
\hline
\end{tabular}

The above Table no. 2 reflects out of 224 respondents, $61.6 \%$ are qualified, $31.7 \%$ are not qualified and $6.7 \%$ are somehow qualified in the use of electronic means. In the same way, $70.7 \%$ respondents focus on face to face contact learning. $18.2 \%$ do not found the necessity of face to face learning. Likewise, only $11.1 \%$ somehow agree in the need of conventional learning. In the same way, $21 \%$ agree whereas $24.1 \%$ disagree and $54.9 \%$ somehow agreethat complete course can be completed effectively through internet. Likewise, out of total sampling of $224,15.9 \%$ agree, $71.3 \%$ disagree and $12.8 \%$ somehow agree that they have their personal smartphones and computers. 


\section{Attitude towards virtual learning in numbers and percent}

Table no.3 Respondents' attitude in numbers and percent

\begin{tabular}{|l|c|c|}
\multicolumn{1}{|c|}{ Variables } & Numbers & Percentage \\
\hline Agree & 70 & 31.3 \\
\hline Somehow agree & 93 & 41.5 \\
\hline Disagree & 61 & 27.2 \\
\hline Total & 224 & 100 \\
\hline
\end{tabular}

The Table 3 reflects out of 224 respondents 93(41.5\%), 70(31.3\%) and 61(27.2\%) are the responses of somehow agree, agree, and disagree respectively. The response of somehow is found to be highest.

\section{E. Association of demographic variables}

Table no.4: Presentation of demographic variables relation

\begin{tabular}{|c|c|c|c|c|}
\hline Variables & Agree & Somehow Agree & Disagree & P-value \\
\hline \multicolumn{5}{|l|}{ Gender } \\
\hline Male & $42(34.7 \%)$ & $44(36.4 \%)$ & $35(28.9 \%)$ & 0.227 \\
\hline Female & $28(27.2 \%)$ & $49(47.6 \%)$ & $26(25.2 \%)$ & \\
\hline \multicolumn{5}{|l|}{ Age Group } \\
\hline Less than 18 & $9(31 \%)$ & $13(44.8 \%)$ & $7(24.1 \%)$ & \\
\hline $18-20$ & $22(23.7 \%)$ & $40(43 \%)$ & $31(33.3 \%)$ & \\
\hline $20-22$ & $19(38 \%)$ & $18(36 \%)$ & $13(26 \%)$ & 0.075 \\
\hline $22-24$ & $10(27 \%)$ & $18(46.6 \%)$ & $13(26 \%)$ & \\
\hline Above 25 & $10(66.7 \%)$ & $4(26.7 \%)$ & $1(6.7 \%)$ & \\
\hline
\end{tabular}

TheTable no.4 shows P-value in terms of gender is 0.227 . It means gender doesn't determine the level of satisfaction in the use of virtual learning. In the same way, at the $10 \%$ level of significance P-value in terms of age is 0.075 . But there is no association for the $5 \%$ level of significance.Here, it shows the higher level of students have more preference towards virtual learning. 


\section{F. Student's Attitude towards Virtual Learning}

Table no. 5: Presentation of attitude towards virtual learning

\begin{tabular}{|c|c|c|c|c|}
\hline Variables & Agree & Somehow Agree & Disagree & P-value \\
\hline \multicolumn{5}{|c|}{ Interest in Virtual learning } \\
\hline Yes & $67(35.4 \%)$ & $74(39.2 \%)$ & $48(25.4 \%)$ & 0.007 \\
\hline No & $3(8.6 \%)$ & & $19(54.3 \%)$ & $13(37.1 \%)$ \\
\hline \multicolumn{5}{|c|}{ Virtual learning in improving skills } \\
\hline Yes & $64(37.6 \%)$ & $64(37.6 \%)$ & $42(24.7 \%)$ & 0.001 \\
\hline No & $6(1.1 \%)$ & & $29(53.7 \%)$ & $19(35.2 \%)$ \\
\hline \multicolumn{5}{|c|}{ Usefulness of virtual learning during lockdown } \\
\hline Yes & $67(34.9 \%)$ & $76(39.6 \%)$ & $49(25.55)$ & 0.015 \\
\hline No & $3(9.4 \%)$ & $17(39.6 \%)$ & $12(37.7 \%)$ & \\
\hline \multicolumn{5}{|c|}{ Problem faced during virtual Learning } \\
\hline Yes & $39(24.5 \%)$ & $72(45.3 \%)$ & $48(32.2 \%)$ & 0.003 \\
\hline No & $31(47.7 \%)$ & $21(32.3 \%)$ & $13(20.0 \%)$ & \\
\hline \multicolumn{5}{|c|}{ Virtual learning in making knowledge wider } \\
\hline Yes & $59(37.3 \%)$ & $54(34.2 \%)$ & $45(28.5 \%)$ & 0.001 \\
\hline No & $11(16.75 \%)$ & $39(59.1 \%)$ & $16(24.2 \%)$ & \\
\hline \multicolumn{5}{|c|}{ Importance of web based teaching for students } \\
\hline Yes & $66(35.1 \%)$ & $76(39.8 \%)$ & $48(25.1 \%)$ & 0.010 \\
\hline No & $3(9.1 \%)$ & $17(51.5 \%)$ & $13(39.4 \%)$ & \\
\hline \multicolumn{5}{|c|}{ Virtual learning in bringing social changes } \\
\hline Yes & $60(39.5 \%)$ & $59(38.8 \%)$ & $33(21.7 \%)$ & 0.001 \\
\hline No & $10(13.9 \%)$ & $34(47.2 \%)$ & $28(38.9 \%)$ & \\
\hline
\end{tabular}

In the above table 5, P- value is computed by chi-square at 5\% level of significance. Out of 224, 67(35.4\%) are interested, 74(39.2\%) somehow interested and 48(25.4\%) are found not interested in virtual learning. 0.005 p-value shows positive association between students' interest and virtual learning. 64(37.6\%) in agree, 64(37.6\%) in somehow agree and $42(24.7 \%)$ have rated in disagree. $0.001 \mathrm{p}$-value presents the positive relation between virtual learning and skill improvement. Likewise, $p$-value 0.015 shows it is significant that virtual learning is useful in lockdown because of covid-19. Similarly, 0.003 p-value indicates those students who didn't face any problem during class have positive attitude towards virtual learning. In the same way, $0.001 \mathrm{p}$-value reflects virtual learning is a tool make knowledge wider. Even $0.010 \mathrm{p}$-value shows there positive relation between virtual learning and importance of web based teaching for students. Moreover, virtual learning is powerful means to bring social changes that is what p-value 0.001 reflects. There is no statistical difference between face to face and online learning in terms of opinion on the ability to increase knowledge( $\mathrm{p}=0.46)$ " (Baczek \& et.al., 2020). Here, this study shows p-value 0.001 in terms of virtual learning in making knowledge wider is quite significant comparing to the above result of Polish research. The cause of variation in result may be that unlike in other discipline, so many practical classes including clinical skills are essential along with direct contact with patients. Content Analysis: It was found conventional learning more preferable. Similarly, 57.7\% students indicates the main reason for limited access is signal availability and strength problem and $30.5 \%$ reflects its high cost. Though the majority of students' preference is for face to face learning, $68.9 \%$ use Wi-Fi of their own, $17.3 \%$ use mobile data and 9.8\% use neighbor's Wi-Fi during covid-19 pandemic. Due to the minimal access to electronic devices, unreliable internet connectivity and unstable power supply students have additional complexity in virtual learning.

\section{Conclusion and Recommendation}

After meticulous analysis of the data it was concluded that majority of students have positive attitude towards 
virtual learning during Covid-19 pandemic. Almost all of the respondents used zoom and Microsoft Teams for learning as they are popular, convenient and easy. Though students faced problem of poor signal availability, strength, high cost, they were interested in virtual learning and also found useful in improving skills for bringing social changes during Covid-19(p-value 0.0010). In the same way, almost all students were qualified to use electronic devices like laptop computer and were comfortable in communicating electronically. In the light of findings, online education is not a substitute but an appendage to classroom teaching. It is temporary aid during difficult situation that all are facing. It posed the great concerns among students and added additional layer of complexity in rural areas where thousands of students are lagging behind with minimal access to electronic devices, reliable internet connectivity or stable electric supply. In this regard, successful implementation of virtual learning into curriculum needs proper policy.

The recommendation of the study is to further explore influencing factors of student's attitude towards virtual learning and to identify the perception of faculties regarding their experiences toward virtual learning during Covid-19 pandemic.

\section{REFERENCES}

Abbasi, S., \& et.al. (2020). Perceptions of students regarding E-learning during Covid-19 a private medical college. doi:https://doi.org/10.12669/pjms.36

Adnan, M., \& Anwar, K. (2020, June 20). Online learning amid the COVID-19 pandemic: Students' perspectives. 2(2020). Pakistan. doi:10.33902/jpsp

Almarzooq, z., Lopes, M., \& Kochar, A. (2020, April). Virtual learning during the COVID-19 Pandemic: A Disruptive Technology in Graduate Medical Education. Journal of the American College of Cardiology. doi:https://doi.org/10.1016/j.jacc.

Amita. (2020). E-Learning Experience of Students in Higher Education Instiututions During the COVID-19 Pandemic: A Primary Survey.

Baczek, M., \& et.al. (2020). Students' Perception of Online learning during the Covid-19 Pandemic : a survey study of Polish. doi:https://doi.org/10.21203/rs.3.rs-41178/v1

Dhawan, S. (2020). Online Learning: A Panacea in the Time of COVID-19 Crisis. doi:10.1177/0047239520934018

Dhull, I., \& Sakshi, M. (2017). Online Learning. 3(8).

Gallagher, R. (2020). Zoom for Online Learning Updatades: Expanded Access for Schools. Retrieved from https://blog.zoom.us/how-to-use-zoom-for-online-learning/

Gautam, D. (2008). Agricultural Development in Nepal: Contribution to Economic Growth, Food Security and Poverty. 1, pp.49-64. Retrieved from https://www.researchgate.net/publication/284165940_Agricultural_ Development_in_Nepal_Contribution_to_Economic_Growth_Food_Security_and_Poverty

Kimovski, G., Trajkovic, V., \& Davcev, D. (2001). Virtual Learning System.

Nations, U. (2020, August). Policy Brief Education during Covid-19 and beyond .

Natoins, U. (2020, August). Policy Brief: Education during COVID-19 and Beyond. Retrieved from /sg_policy_ brief_covid-19_and_education_august_2020.pdf

Nguyan, T. (2015). Effectiveness of Online Learning: Beyond No Significant Difference and Future Horizons. MERLOT Joournal of Online Learning and Teaching, 11.

Piccoli, G., Ahmad, R., \& Ivs, B. (2001). Web-Based Virtual Learning Environments: A Research Framework And A Priliminary Assessment Of Effectiveness In Basic IT Skills Traninig. 25, 401-426.

Policy Brief:Education during Covid-19 and beyond. (2020, August). United Nations.

UNESCO. (2020, April 9). COVID-19 and higher education: Today and Tomorrow Impact Analysis Policy responses and recommendations, 1-46. Retrieved from file:///C:/Users/TCC-DELL/Desktop/PDFs\%20 for\%20virtual\%20learning/COVID-19-EN-090420-2.pdf

Wikipedia. (n.d.). Retrieved from https://en.wikipedia.org/wiki/Main_Page 